ESJ Social Sciences

\title{
An Interview with Antti Juvonen: Creativity, Talent and Giftedness in Finland
}

\author{
Michael F. Shaughnessy \\ Kaitlyn Beaudet \\ Eastern New Mexico University, USA
}

Doi:10.19044/esj.2021.v17n8p1

Submitted: /

Accepted: /

Published: 31 March 2021
Copyright 2021 Author(s)

Under Creative Commons BY-NC-ND

4.0 OPEN ACCESS

Cite As:

Shaughnessy M. and Beaudet K. (2021). An Interview with Antti Juvonen: Creativity, Talent and Giftedness in Finland. European Scientific Journal, ESJ, 17(8), 1. https://doi.org/10.19044/esj.2021.v17n8p1

\section{Abstract}

- In your opinion, how well does Finland teach, mentor, coach and help gifted and talented and creative students?

I suppose you mean the school education context. I am afraid that gifted, talented and creative students have been almost forgotten in our Finnish school system. I believe that the only thing that is currently being done for gifted, talented and creative pupils is differentiating upwards, which means in practice, offering them some extra exercises. This is mostly because in Finland we have a system where pupils with special needs are put in normal classes with other pupils. It is called inclusion. Pupils with special needs have been supported with a so called "three step support" since 2011.

The first step is general support which the teacher offers with individual pedagogical solutions.

The second step is aimed for pupils with long-lasting wider needs for support. It is called intensified support. If this does not help the pupil, the system offers specific support which can be offered after quite comprehensive studies are made by psychologists and other specialists. The idea of this model was to help all pupils to get as good and comprehensive an 
education as possible. What went wrong was that the cities and especially small towns, did not hire enough helping personnel to support the pupils with special needs.

This causes big challenges to class teachers who are put in a position of a special education teacher: they have to take care of pupils with special needs, but at the same time they should be able to teach the rest of the class with normal level pupils and the gifted, talented and creative pupils.

Of course, the pupils with special needs take most of their time, which means that the others must try to learn at least the minimum of the curriculum's requirements. The most gifted often become frustrated and start inventing activities which also disturb the classroom action and atmosphere. This happens because they are bored and do not get any response or activation or response for their innovativeness or special gifts. So, as a whole I see the situation quite poor from the point of view of those groups mentioned.

\section{Keywords: Creativity, Talent, Interview}

1) In your opinion, how well does Finland teach, mentor, coach and help gifted and talented and creative students?

I suppose you mean the school education context. I am afraid that gifted, talented and creative students have been almost forgotten in our Finnish school system. I believe that the only thing that is currently being done for gifted, talented and creative pupils is differentiating upwards, which means in practice, offering them some extra exercises. This is mostly because in Finland we have a system where pupils with special needs are put in normal classes with other pupils. It is called inclusion. Pupils with special needs have been supported with a so called "three step support" since 2011.

The first step is general support which the teacher offers with individual pedagogical solutions.

The second step is aimed for pupils with long-lasting wider needs for support. It is called intensified support. If this does not help the pupil, the system offers specific support which can be offered after quite comprehensive studies are made by psychologists and other specialists. The idea of this model was to help all pupils to get as good and comprehensive an education as possible. What went wrong was that the cities and especially small towns, did not hire enough helping personnel to support the pupils with special needs. 
This causes big challenges to class teachers who are put in a position of a special education teacher: they have to take care of pupils with special needs, but at the same time they should be able to teach the rest of the class with normal level pupils and the gifted, talented and creative pupils.

Of course, the pupils with special needs take most of their time, which means that the others must try to learn at least the minimum of the curriculum's requirements. The most gifted often become frustrated and start inventing activities which also disturb the classroom action and atmosphere. This happens because they are bored and do not get any response or activation or response for their innovativeness or special gifts. So, as a whole I see the situation quite poor from the point of view of those groups mentioned.

2) How are they identified or tested?

Actually, they are not tested with any special tests. Usually, a wise teacher notes early on some pupils' abilities and special giftedness even in the first classes. The school age in Finland begins in the year when the children become seven years old. For different reasons it can be brought forward or delayed one year. For example, I started my school when I was six years old.

Often the special gifts are revealed through the children's hobbies. The traditional hobbies such as music, painting, drawing, sports, often show also children's talents at schoolwork.

Today, there are also several new areas of talents and giftedness, for example in connection with IT or smartphones iPads etc.

Giftedness may also show in usual schoolwork in many ways, but identifying it requires a wise insightful teacher. Not all teachers can recognize different talents. Actually, I am starting a major research endeavor among all school levels concerning traditional hobbies, but also other activities which youngsters conduct in their leisure time including taking photographs, making films, making music, drama or using other areas of their creativity. These activities are often passed by because they are not seen as "hobbies" in the traditional sense although they may include great amounts of creativity and giftedness.

3) How do you think being "labeled " affects them and their parents?

It depends a lot of the parents. My opinion is that they (those who are "labeled") should be encouraged and supported in all possible ways, but they should not be lifted up so that they start thinking that they are something 
special. I have seen many examples where talented children (musicians) have become too proud even to say hello to their peers. That is a wrong path.

I think that it is mostly the parents' responsibility to keep their children's feet on the ground so to speak. Thinking too much of oneself may also cause a lot of troubles in the future when the truth is revealed.

It is natural that parents are proud of their children when they show success and show their talents, but this should not be the most important thing in their life. The target should be growing children to become happy and harmonized or well adjusted citizens who can use their gifts to reach valuable and meaningful targets in their life.

4) Does the gifted label affect non-gifted students just as much as gifted students?

If so, how?

In a group of students, for example in teacher education where I work, in music specialized studies groups there are always those who are better instrumentalists or singers than the others. If they behave nicely and politely while playing and singing with the others, everything can go smoothly without any difficulties or troubles. But if the gifted start to pressurize or bully the less gifted, the problems begin. The atmosphere drops or changes immediately and the non-gifted may even leave the studies for this reason. It may cause big traumas and difficult situations. This also depends on the teacher who can act in a way where these differences do not cumulate. This can be done emphasizing different kinds of giftedness and encouraging everyone in developing their special gift areas as well as those areas which still need to become better or show improvement or growth and development.

5) How can we support creative students and encourage creativity in colleges and universities (societies at-large) that are becoming increasingly standardized or rationalized?

At least we can encourage creative students in choosing the subjects of their master degree and even doctoral degree thesis so that they can use their creativeness in them. It means often breaking the traditional rules which causes extra work and sometimes difficulties in getting the works accepted. I remember one student who wanted to write his master's thesis using poetry meter. It was quite difficult to find another evaluator for it. Another student made his master's thesis as a short film about pupils exploring the nature phenomena. 
Another way of supporting students in creativity is showing an example: if we can raise general interest in issues which require creativity, maybe it encourages the students to also do the same.

I don't believe that we academics could somehow affect the society and its rationalization or standardization. Unfortunately, it seems that in societies today, money and economical solutions are the only ones which rule.

6) Is creativity linked to resilience? (or as the Finnish say "grit"?)

I believe that it is, at least in some cases when the creative solution is not easily found. The famous Finnish "grit" has surely helped in finding solutions in many creativity-requiring issues, but grit does not offer solutions alone. Maybe it is in close connection with such situations where much trial and error -type exploration is needed. Resilience, commitment and imagination are all needed in finding creative solutions.

7) And is creativity perhaps linked to resistance- in terms of being determined by others?

Creativity often collapses with the resistance of less creative people, because creative solutions usually differ from traditional and familiar ones. Understanding creative ideas require an ability to disengage oneself from normal ways of acting and thinking. In Finland, we used to have so called "village idiots" in almost every small village. They were often misunderstood creative persons who could not express their creativity in traditional ways. Also, some artists raise resistance with their works and there are several whose works did not get any appreciation during their lifetime, but were valued high after their death.

8) How can we foster resilience or grit in academic settings, especially in gifted/talented populations?

The best ways of supporting creativity are, freedom of choice, offering enough time and space, freedom to make mistakes, and positive, encouraging atmosphere. All these are connected to resilience and offer the best opportunities to successful creative solutions. In Finland, people are used to living in quite harsh conditions, the weather sets challenges and also the geographic location has during the history taught its lessons to people.

I think that it is because of those challenges that Finns have gained the "grit". So, my opinion is that winning big and difficult challenges offers an 
opportunity to grow and develop resilience. We must offer suitable challenges to our students and encourage them to overcome them in style of "everything is possible, when you try hard enough".

9) Does the encouragement of creativity necessitate one's involvement in mundane tasks?

I think that creative solutions can occur in mundane tasks as well as elsewhere. They may be small new solutions in everyday problems connected to food-making, furnishing, renovating one's own home etc. Another issue is solving for example philosophical questions, or scientific problems which have no connection to mundane tasks. They often require disengaging oneself from everyday environment to be able to contemplate solutions in perfect peace.

10) Does creativity need to be productive?

My opinion is that it does not need to be productive. Creativity does not require some touchable or tangible product as a target. The output of creativity can be an idea or a new way of thinking, a philosophical structure or a new way of looking at the world. It could be also a piece of music improvised only once which disappears immediately after playing it with a musical instrument.

11) How does this relate to how we engage with creativity both as educators and as students?

First of all, we should be able to set students questions which do not have only one right answer. But on the other hand, we should encourage students to challenge themselves with difficult questions which require creativity to answer. Finding creative solutions to problems together with students not as teachers, but as peer researchers might be one way of acting. One example of fostering creativity was when one of our music teachers made students create music to TV advertisements which were muted. The results were in many cases much better than the original compositions in the advertisements. The use of smart technology, phones, iPads, computers and all their applications offer a great field or outlook for creativity today. All of our students have some gadget which can be used in creating new options or alternatives. The teachers must be creative all the time to make their students also creative. 


\section{2) Does creativity require vulnerability? Or high emotionality?}

I don't think that creativity in itself requires vulnerability, but in some cases, it may help in finding creative solutions. When you are vulnerable, your senses may work more delicately which may open doors which usually do not open in your mind. High emotionality is needed when we are dealing with problems between individuals. In such cases, high emotionality helps in sensing the atmosphere and changes it, which may help finding creative solutions in problems which may be mental, spiritual or even intellectual.

13) Can creativity ever be detrimental to the creative individual or their society? Or does it yield positive results at all times?

Creativity cannot be detrimental, but it can be used detrimentally to cause harm to others. If we think about great geniuses like Einstein who used his creativity in developing the theory of relativity or Oppenheimer who developed the atomic bomb, it is difficult to say whether their creative inventions are detrimental, or profitable considering that they can destroy the whole planet Earth. Creative solutions can also be used in bad aims in interaction between people. As a whole, my opinion is that creativity offers more positive results than negative.

14) Does the ethos and values of a society/culture influence how creativity is manifested on the individual level?

If we look at the history of creativity, it is easy to see that in some cultures and in some time eras there have been periods of time when creativity has blossomed strongly; for example the Renaissance in Europe. Some decades ago, Japan was seen as an innovative society as new inventions were brought up frequently.

In Finland, we had a government with Matti Vanhanen as the prime minister, and that government wrote in their government platform that innovation should be the driving force of our competitiveness and economic growth. This shows that there have been plans of reaching an ethos of creativity. Unfortunately, Matti Vanhanen's ideas did not spread widely, so that I could say that they had any kind of impact on any individual level.

But I don't think that it is impossible to reach in right circumstances and when right or prudent or correct decisions are made at the governmental level. Usually, creativity is present in speeches when the elections become close. The politicians then speak loudly about the advances of arts and skills and creativity, but as soon as they are elected, they forget about these and concentrate on economically profitable issues. 
Creativity at work is also dependent on the leadership in working places. Leaders can guide the morals to a positive direction. Unfortunately, there are organizations where workers cannot use their creativity or special gifts.

The leader should do whatever is possible to motivate workers to do their best. Most important is to find the significance, meaning and purpose of work. An innovative organization supports creativity and makes the work possible. Still, often creativity is killed or perhaps stifled, in the name of productivity, unity or controlling. The leading politicians and business world's key actors decide which is more important: creative work or compulsive profit making. These decisions have a big impact on the life of families, children and future generations.

15) How does creativity relate to morality? Especially in its Western conception?

There are many ways how creativity is connected to morality. One example is inventing and creating new games. Game-builders use their creativity to build new games which hook players in an addictive manner to spend their money on playing these games. That is when the creativity is used against morals and ethics. These games are planned so that they restrain certain behavior and promote some other kind of behavior. The games have some kind of structural presumptions about what kind of playing should be successful. These are built on values which reflect moral and ethical starting points. For example, the shooting game "Counter Strike" is full of fictional violence and killing which are quite opposite to everyday morals. In this way of thinking both the game creators and players share ethical responsibility of the ethical choices.

Howard Gardner also wrote about "good work" which he defined with three E-letters: Excellence, Engagement and Ethics, meaning that the work must be done as well as we can, we must be engaged to it and remember all of the time that there are ethical issues of which we must be aware.

16) How can mentoring and mentors help with creativity and the development of musical talent?

There are big problems concerning creativity and developing musical talent. These problems mostly concentrate in the relationship between the teacher and the pupil. In Finland, for example there is a good music school and conservatoire system not to mention the Sibelius Academy, which have been able to educate a lot of great musicians, singers and composers. Still, there are a lot of drop outs who have started to hate music and instrument playing, composing, etc. 
The traditional music teaching is based on journeyman - master -type teaching and learning where the young student tries to imitate and copy the skills of the master. In this type of learning it is not about mentoring, it is a dictatorial relationship where the master rules everything: the program played, the schedule, the performances: when, what, where etc. The pupil lacks all decision-making opportunities. In addition to this, the traditional master-type teachers often believe that only they have the "right" knowledge and know-how of teaching music. This is an explanation for so many drop outs from Finnish music education.

The music educational associations have tried to turn the direction of teaching towards a socio-constructivist teaching and learning conception, and in some areas they have even succeeded. Still, there are lots of oldschool teachers working in music institutes who can't, or will not change their methods towards modern methods including mentoring and cherishing the pupil's creativity and own motivation to make music. Unfortunately, the new teachers tend to teach the same way as they were taught, which keeps the old wheel rolling, and the mistakes repeated again.

17) What have we neglected to ask?

These questions have been very interesting and they have given me a lot to think about. I believe, that it is impossible to change anything without discussing these matters, often in person and in depth. That is why this kind of interviews may be valuable in the way to reaching a better, more creative and joyful life. 